\title{
PERCEIVED ORGANIZATIONAL INJUSTICE, JOB SATISFACTION, ORGANIZATIONAL COMMITMENT, AND TURNOVER INTENTION: A STUDY OF MNCs IN MALAYSIA
}

\author{
Daisy Mui Hung Kee* \\ Universiti Sains Malaysia, Penang, Malaysia \\ Kuok Shiong Chung \\ Broadcom Inc, Penang, Malaysia
}

\begin{abstract}
The paper intends to examine the relationship between perceived organizational injustice, organizational commitment, and turnover intention. Besides, the paper investigates the mediating role of job satisfaction on the relationship between organizational injustice, organizational commitment, and turnover intention. The presence of gender as a moderating role is also tested. Testing hypotheses on 203 MNCs employees, the paper finds that distributive and interactional injustice are associated with organizational commitment, job satisfaction, and higher turnover intention. Procedural injustice has a direct negative influence on job satisfaction. Job satisfaction has a mediating effect on the relationship between organizational injustice, organizational commitment, and turnover intention. Gender is found to have a moderating effect on the relationship between organizational injustice and turnover intention. This study's findings serve as guidelines to help managers better understand organizational behaviors, specifically on how to minimize employee turnover, improve job satisfaction and organizational commitment, and make better decisions in managing the perception of distributive and interactional injustice when dealing with their employees.
\end{abstract}

Keywords: Organizational Injustice, Organizational Commitment, Job Satisfaction, Turnover Intention, Gender, MNCs, Malaysia.

Received: 6 October 2019

Accepted: 27 April 2021

https://doi.org/10.33736/ijbs.3781.2021

\section{INTRODUCTION}

As organizations grow, human capital is the crucial element that drives the growth of an organization. Therefore, an organization's ability to retain its high performing employees will bring great reward and success to the organization itself. Organizations need to pay more considerable attention to vital organizational behaviors such as employee job performance, commitment, and job satisfaction since organizational outcomes or behaviors may affect organizational performance (Rubel \& Kee, 2015a, 2015b; Ansari et al., 2007, 2008; Kee et al., 2004; Chen et al., 2006). One of the most prominent factors that may affect organizational

\footnotetext{
- Corresponding author: School of Management, Universiti Sains Malaysia, 11800 Penang, Malaysia; Tel: 0164151915 ; Email: daisy@usm.my
} 
behaviors is organizational justice, which according to Greenberg (1993), an individual's perception of justice or fairness about treatment received from an organization and the behavioral responses to such perceptions.

Where the main problem lies? There was no single word that comes to define perceived injustice as much as 'unfairness.' Searching in the Internet dictionary led to a realization that 'fair' has been defined as (a) free from bias, dishonesty, or injustice, equitable, impartial, legitimate, following the rules or standards; and (b) offering an equal chance of success. Cohen (1986, p.4) defined justice as "a central moral standard against which social conduct, practice, and institutions are evaluated." In other words, 'fairness' embodies the concepts of justice and 'rightness.' To be treated 'fairly' or justly means that one is treated according to the established rules or standards in our community today; and treated in the same unbiased, equitable way as one's colleagues, neighbors, or friends. 'Fairness' is an attitude of mind that influences judgments. The difference between 'what we perceive' and 'what we expect to perceive' drives us to explain 'justify' behaviors or treatments. If a justification cannot be found, a sense of unfairness or injustice can affect us emotionally and behaviorally, eventually affecting organizational performance. In this paper, organizational injustice refers to employee perceptions of unfairness at the workplace. While organizations strive towards becoming lean and cost-effective under current global economic conditions, the issue of justice is again under the spotlight. Under pressure to perform, organizations must take various actions to improve operating margin and net profit through expense reduction. Of all those actions taken, activities that involved cost reduction have an impact on employees. Employees tend to view such measures or actions taken as unfair and merely an act of injustice. As a result, employees create a feeling of unappreciation, and thus, in the long run, their level of satisfaction and commitment will be severely affected.

Consequently, the perception of injustice over time forms in organizations and somehow influences many critical factors in organizational behaviors, especially its employees' well-being. Understanding how the organizations and employees contribute to resolving this perception of injustice is critical to finding ways to connect employees to organizations psychologically and facilitate employees' effectiveness in their job. This study investigates the relationships among organizational injustice, organizational commitment, and turnover while considering job satisfaction as a mediating factor and gender as a moderator. Previous literature mainly focuses on organizational justice, while this paper extends existing research on organizational injustice and how it influences MNCs employees' attitudes and behaviors at work.

\section{LITERATURE REVIEW}

The paper conceptualizes organizational injustice into three dimensions, namely distributive, procedural, and interactional. Distributive injustice refers to the perceived unfairness of how resources and rewards are being distributed throughout an organization. Procedural injustice is the perceived unfairness of the means used to determine those amounts (Folger \& Konovsky, 1989). Interactional justice is defined as "the interpersonal treatment that employees receive during the enactment of organizational procedures" (Bies \& Moag, 1986, p. 44). Bies and Tripp (2001) argue that interactional justice can be distinguished from procedural justice. The debate on a new dimension of organizational justice has created a cloudy arena. However, studies have 
found that interactional justice did make a distinctive contribution in explaining many organizational outcomes (Cohen-Charash \& Spector, 2001; Colquitt et al., 2001).

Organizational commitment and turnover intention are the dependent variables of the study. Porter et al. (1974) conceptualized organizational commitment as having faith in and overall accepting organizational goals, willingly working for the organization, and desire to remain with the organization. Mowday et al. (1982) defined organizational commitment as the relative strength of an employee's identification with and involvement in an organization. Mowday and Steers (1979) found a positive relationship between job satisfaction and organizational commitment. Past studies reported negative relationships between organizational commitment and turnover intention (Rubel \& Kee, 2015a, 2015b; Ansari et al., 2007; Kee et al., 2004). A couple of studies on gender as the moderating factor on organizational commitment observed that females were more committed than males (Angle \& Perry, 1981). The issue of organizational commitment has continued to be a vital aspect for managers in organizations. In today's world of fast speed and degree of change in organizations, managers continuously look for ways to enhance and inculcate employees' commitment and competitive advantage.

Mobley et al. (1978) defined turnover intention as voluntarily leaving a job. Turnover intention can be described as a plan to switch employer voluntarily. Employee retention has become a significant challenge facing many organizations today. Extensive empirical research has been performed in the past on the relationship between HR practices and employee turnover, particularly from the organizational perspective (Kee et al., 2020; Paul \& Kee, 2018, 2020; Rubel et al., 2020; Rubel \& Kee, 2015a: 2015b; Rubel et al., 2018). The turnover process typically means separation or the severance of the relationship between an individual employee and the organization. Since employee turnover has a substantial impact on an organization's operation and cost, both academic scholars and practitioners continue to seek strategies that encourage employees to stay (Rubel et al., 2017). Employee retention is typically a much better investment than recruiting new employees for replacement (Mitchell et al., 2001). The study employs turnover intention because the turnover intention is the strongest predictor of actual turnover in organizations (Mowday et al., 1982).

Job satisfaction is one of the most important work-related attitudes and most frequently studied in organizational behavior. Greenberg and Baron (1997) defined job satisfaction as employees' responses to their job. The paper suggests that job satisfaction is a potential mediator in the relationship between perceived organizational injustice, organizational commitment, and turnover intention. Also, the paper proposes gender moderates in the above relationship. The basic premise of social exchange theory (SET) is that relationships providing more rewards than costs will yield enduring mutual trust and attraction (Blau, 1964). Blau (1964) defines social exchange as individuals' voluntary actions driven by the expected returns they will receive due to their voluntarily initiated behaviors. In other words, SET involves a series of interactions that result in obligations among those engaged in the exchange process. This study suggests that job satisfaction and organizational commitment are channels through which employees may reciprocate or return the favor rendered by employers who well-treat them. For example, employers treat the employees fairly. Hence, this favor on employers causes an obligation on employees to reciprocate through job satisfaction and organizational commitment. The exchanged favors are indicators of investment in the relationship and mutual support. The SET theory suggests that employees are motivated to engage in job satisfaction and organizational 
commitment based on a fair social exchange. In other words, if the employees perceive that they are treated unfairly, then employees are more likely to leave the organization. In this respect, the SET is applicable to understand better the effects of employers-employees interactions in the context of organizational injustice, job satisfaction, organizational commitment, and turnover intention. Figure 1 presents a research framework demonstrating the relationship between organizational injustice, job satisfaction, organizational commitment, and turnover intention.

Figure 1: Proposed Research Framework

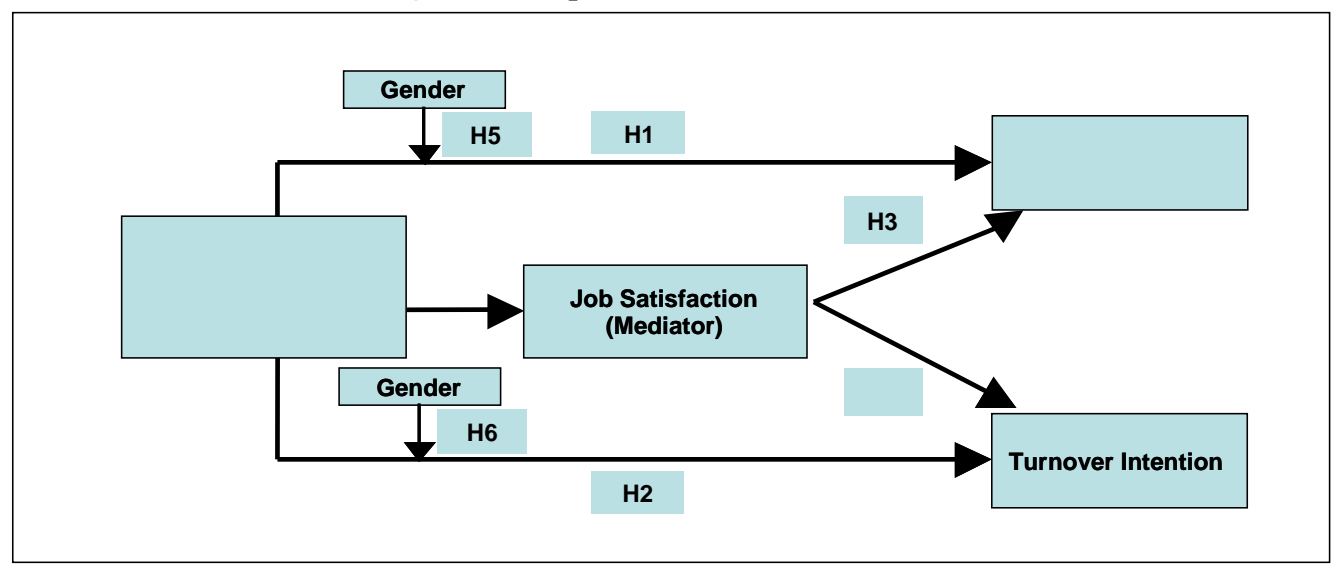

One of this study's main research objectives is to examine the relationship between organizational injustice and organizational commitment. Previous studies have predicted that high organizational justice would result in high organizational commitment (Ansari et al., 2008; Luo, Marnburg \& Law, 2017; Kaul \& Singh, 2017; Kauppila et al., 2018; Cohen-Charash \& Spector, 2001; Colquitt et al., 2001). However, there is no study done on organizational injustice to organizational commitment. Therefore, to reaffirm the above findings from the perspective of organizational injustice, the following hypotheses are proposed:

H1a. Perceived distributive injustice is negatively related to organizational commitment.

H1b. Perceived procedural injustice is negatively related to organizational commitment.

H1c. Perceived interactional injustice is negatively related to organizational commitment.

Similarly, previous studies also predicted that high organizational justice would result in low withdrawal behaviors such as turnover intentions. Therefore, it is assumed that organizational injustice may lead to a high turnover intention among employees. Drawing on this assumption, the second hypothesis was formed:

H2a. Perceived distributive injustice is positively related to turnover intention.

H2b. Perceived procedural injustice is positively related to turnover intention. 


\section{H2c. Perceived interactional injustice is positively related to turnover intention.}

Previous studies have shown that some form of relationship exists between job satisfaction and organizational commitment, but there have been several ongoing debates about the relationship's direction. The main observation is that job satisfaction is an antecedent of organizational commitment (Cugueró-Escofet et al., 2019; Mowday et al., 1982; Williams \& Hazer, 1986). Research by Steers (1977) suggested that employees are likely to be more committed when their needs are satisfied by the organization. Past studies from Vandenberg and Lance (1992) supports that organizational commitment is an antecedent to job satisfaction. Another group views the relationship as a mutual one (Price \& Mueller, 1981; Lance, 1991). Given this inconsistency, this study intends to investigate the relationship between job satisfaction and organizational commitment and investigate whether job satisfaction will mediate the relationship between organizational injustice and organizational commitment. Employees who perceive that justice exists in an organization are likely to be satisfied with their jobs, which is expected to increase their organizational commitment. The mediating role of job satisfaction is supported by CugueróEscofet et al. (2019). Based on this assumption, the following hypotheses are proposed:

H3a. Job satisfaction mediates the relationship between perceived distributive injustice and organizational commitment.

\section{H3b. Job satisfaction mediates the relationship between perceived procedural injustice and organizational commitment.}

\section{H3c. Job satisfaction mediates the relationship between perceived interactional injustice and organizational commitment.}

Similarly, this study believes that job satisfaction mediates the relationship between organizational injustice and turnover intentions in organizations. Employees who perceive organizational injustice being practiced are likely to be dissatisfied with their jobs, which are expected to influence the cognitive response, leading to behavioral intentions to leave the organization. Based on this assumption, the following hypotheses were, therefore, framed:

\section{H4a. Job satisfaction mediates the relationship between perceived distributive injustice and turnover intention.}

\section{H4b. Job satisfaction mediates the relationship between perceived procedural injustice and turnover intention.}

\section{H4c. Job satisfaction mediates the relationship between perceived interactional injustice and turnover intention.}

The increasing literature on gender differences in women's career paths and work experiences in the accounting field found that the level of work commitment is not associated with gender (Pillsbury et al., 1989). On the contrary, a couple of studies on gender as the moderating factor on organizational commitment observed that females were more committed than males (Angle \& Perry, 1981). This is also supported by studies from Major and Deaux (1982) that found females react less negatively than men when they are treated unfairly by a partner. Therefore, this study 
investigates the moderating effect of gender on the relationship between organizational injustice and organizational commitment. Thus, the below hypotheses are specifically formed.

H5a. The negative relationship between perceived procedural injustice and organizational commitment is stronger in females than in males.

H5b. The negative relationship between perceived distributive injustice and organizational commitment is stronger in females than in males.

H5c. The negative relationship between perceived interactional injustice and organizational commitment is stronger in females than in males.

Rasch and Harrell (1990) discovered that senior female members somehow demonstrated higher turnover intention than males. On the other hand, Sweeney and McFarlin (1997) found that procedural justice has more impact on females regarding their intention to stay in an organization than males. This study investigates the influence of gender on the relationship between organizational injustice and turnover intentions. Therefore, the hypotheses are specifically formed.

H6a. The positive relationship between perceived procedural injustice and turnover intentions is stronger in females than in males.

H6b. The positive relationship between perceived distributive injustice and turnover intentions is stronger in females than in males.

H6c. The positive relationship between perceived interactional injustice and turnover intention is stronger in females than in males.

\section{METHODOLOGY}

\subsection{Data and Sample}

The study tested hypotheses using a sample of 203 employees in MNCs with organizational sizes ranging from medium to large size. These MNCs were involved in manufacturing, research, and development activities and designing electronic chips such as ASSPs, ASICs, FPGAs, microprocessors, flash memory, microcontrollers. These MNCs were well established and have been in the industries for more than five years. Therefore, these MNCs' organizational structures were clearly defined, and each department has its functions and responsibilities and clear reporting structures. Data collection was done through a structured questionnaire distributed via hardcopy by the researchers and close friends who work in MNCs.

Table 1 presents a summary of the participants' profiles. Over half of the participants were male (56.7\%). Approximately three quarters were Chinese (72.4\%). 50.2\% of participants were 21-30 years old, and $46.3 \%$ were $31-40$ years old. $97.1 \%$ of participants held a master's or bachelor's degree, indicating this was a highly educated sample. While $40 \%$ and $30 \%$ of the participants were middle management (section head and section manager) and lower management (comprises 
engineering group lead/line supervisor), about $24 \%$ were in the technical/individual contributor category. Finally, 59.1\% worked with the organization between 1 to 5 years, and another $34.5 \%$ worked with the organization between 6 to 10 years.

Table 1: Participants' Demographic Profile

\begin{tabular}{llrr}
\hline \hline Variable & Category & Frequency & Percentage (\%) \\
\hline \multirow{2}{*}{ Gender } & Male & 115 & 56.7 \\
& Female & 88 & 43.3 \\
\hline \multirow{3}{*}{ Age } & 21-30 years & 102 & 50.2 \\
& 31-40 years & 94 & 46.3 \\
& 41-50 years & 7 & 3.5 \\
\hline \multirow{5}{*}{ Race } & Malay & 33 & 16.3 \\
& Chinese & 147 & 72.4 \\
& Indian & 20 & 9.8 \\
\multirow{3}{*}{ Education Level } & Others & 3 & 1.5 \\
& Diploma & 6 & 2.9 \\
& Degree & 164 & 80.8 \\
\multirow{3}{*}{ Job Position } & Master & 33 & 16.3 \\
\hline & Top Management & 12 & 5.9 \\
& Middle Management & 81 & 39.9 \\
& Lower Management & 61 & 30.1 \\
\multirow{3}{*}{ Organizational Tenure } & Technical/Individual Contributor & 49 & 24.1 \\
\hline \hline & 1-5 years & 120 & 59.1 \\
& 11-15 years & 70 & 34.5 \\
& 16-20 years & 10 & 4.9 \\
\hline
\end{tabular}

\subsection{Research Design}

The study was designed as a cross-sectional design, analyzing the data from first-hand (survey) data collection. There is no manipulation of independent variables (e.g., organizational injustice). Thus, this study performed confirmatory analysis on the relationship between the independent and dependent variables identified earlier. This study mainly focuses on employees from semiconductor based MNCs in the state of Penang, Malaysia. The study employed the judgment sampling technique. The sample must meet the criteria that the participants were full-time employees who have worked in MNCs for at least one year. Full-time employees with at least one year of employment were considered because the researchers argue that employment duration is essential in obtaining a more accurate and fair evaluation. A pre-test was conducted to examine the survey questions' clarity and see if improvement can enhance participants' understanding and interest while maintaining a suitable survey length. The pre-test survey was distributed to three MNCs HR managers to check if the questionnaire was straightforward and precise. Some questions were fine-tuned and revised. 


\subsection{Measures}

All measures were anchored using a 5-point Likert scale with the responses ranged from 1 ("Strongly Disagree") to 5 ("Strongly Agree"). A summary of the measurement instrument is shown in Table 2.

Table 2: A Summary of Measurement Instrument

\begin{tabular}{llcr}
\hline \hline Variables & Source & Items & Cronbach Alpha \\
\hline Distributive Injustice & & 5 & \\
Procedural Injustice & Niehoff \& Moorman (1993); Colquitt et al. (2001) & 6 & $0.79-0.91$ \\
Interactional Injustice & & 8 & \\
Organizational & Mowday \& Steers (1979) & 8 & 0.83 \\
Commitment & Bluedorn (1982) & 4 & 0.90 \\
Turnover Intention & Al-Dmour \& Awamleh (2002) & 5 & 0.88 \\
Job Satisfaction &
\end{tabular}

Distributive injustice. Using the scale developed by Colquitt et al. (2001) and Niehoff and Moorman (1993), participants rated five statements describing their view on the extent to which they feel that they are unfairly rewarded for their contribution to the organization.

Procedural injustice. Following the work of Colquitt et al. (2001) and Niehoff and Moorman (1993), participants were asked to provide their views on six statements related to the general work procedures used in their organizations. An example of the item includes "My manager is biased in making job decisions affecting me."

Interactional injustice. Interactional injustice was measured with ten items from Colquitt et al. (2001) and Niehoff and Moorman (1993). This injustice refers to the diplomatic communication of results and expressions of honesty in a conversation and if employees felt they are being treated with respect and dignity.

Organizational commitment. Organizational commitment was measured with eight items from OCQ developed by Mowday and Steers (1979). Organizational commitment refers to the desire to stay put with an organization.

Turnover intention. To assess turnover intention, four items were adapted from Bluedorn (1982). Turnover intention refers to the thoughts of the employee concerning leaving the organization voluntarily.

Job satisfaction. Job satisfaction was assessed on a five-item scale that was developed by Al-Dmour and Awamleh (2002).

\subsection{Statistical Analysis}

Data collected from the questionnaires were analyzed using the SPSS. Initially, the data obtained were subjected to data cleaning before performing factor analysis and Cronbach Alpha tests to verify data validity and reliability. Multiple regression analysis was performed along with other 
statistical analyses to verify the hypotheses formulated initially for this study. The effect of job satisfaction as a mediating factor, together with the moderating effect by gender, was assessed.

\section{RESULTS}

Table 3 presents descriptive statistics, reliability information, and zero-order correlations among study variables.

Table 3: Descriptive Statistics, Cronbach's Coefficients Alpha, and Zero-order Correlations of All Study Variables

\begin{tabular}{lrrrrrr}
\hline \hline Variables & $\mathbf{1}$ & $\mathbf{2}$ & $\mathbf{3}$ & $\mathbf{4}$ & $\mathbf{5}$ & $\mathbf{6}$ \\
\hline 1. Interactional Injustice & $\mathbf{0 . 8 9}$ & & & & & \\
2. Distributive Injustice & $.56^{* *}$ & $\mathbf{0 . 9 1}$ & & & & \\
3. Procedural Injustice & $.54^{* *}$ & $.44^{* *}$ & $\mathbf{0 . 6 2}$ & & & \\
4. Organizational Commitment & $-.73^{* *}$ & $-.70^{* *}$ & $-.49^{* *}$ & $\mathbf{0 . 9 1}$ & & \\
5. Turnover Intention & $.65^{* *}$ & $.62^{* *}$ & $.48^{* *}$ & $-.81^{* *}$ & $\mathbf{0 . 8 8}$ & \\
6. Job Satisfaction & $-.74^{* *}$ & $-.80^{* *}$ & $-.55^{* *}$ & $.87^{* *}$ & $-.69^{* *}$ & $\mathbf{0 . 8 9}$ \\
\hline Mean & 2.72 & 3.41 & 3.04 & 3.25 & 3.04 & 2.95 \\
\hline Standard Deviation & 0.77 & 1.02 & 0.86 & 0.76 & 0.93 & 0.87 \\
\hline No. of Items & 6 & 3 & 2 & 8 & 4 & 5 \\
\hline \hline Note: $\mathrm{N}=203 ; * \mathrm{p}<.05, * * \mathrm{p}<.01,{ }^{* * *} \mathrm{p}<.001$ Diagonal entries indicate Cronbach's coefficients alpha.
\end{tabular}

Hypothesis 1 examines the relationship between organizational injustice and organizational commitment. A regression analysis was conducted to test the hypotheses. Three organizational injustices were entered as independent variables, while organizational commitment was entered as the dependent variable. Distributive and interpersonal injustice were found statistically significant with organizational commitment. The relationship between distributive and interpersonal injustice was negatively correlated to organizational commitment with beta values of -.41 and -.48 . The value of $\mathrm{R}^{2}$ shown was .66 , which means that $66 \%$ of the variation in organizational commitment is explainable by organizational injustice. The results showed that procedural injustice was statistically insignificant in influencing organizational commitment. Thus, H1 was partially accepted as only H1a and H1b were accepted while H1c was rejected. The results were tabulated in Table 4. Hypothesis 2 assesses the relationship between organizational injustice and turnover intention. The results demonstrated that procedural injustice was, however, statistically insignificant in influencing turnover intention. Thus, $\mathrm{H} 2$ received partial support as $\mathrm{H} 2 \mathrm{a}$ and $\mathrm{H} 2 \mathrm{c}$ were accepted, while $\mathrm{H} 2 \mathrm{~b}$ was rejected.

Hypothesis 3 predicts that the relationship between organizational injustice and organizational commitment is mediated by job satisfaction. As shown in Table 4, both distributive and interactional injustice were significantly related to job satisfaction with beta values of -.54 and .39 , respectively. The effect of job satisfaction on organizational commitment showed a significant relationship with a beta of .71 . While the distributive injustice dimension was reduced from a significant beta value of -.41 to non-significant, interactional injustices were reduced from -.48 to -.20 but remained statistically significant. $\mathrm{R}^{2}$ improves from .66 to .78 after the addition of job satisfaction as a mediator. The results showed that job satisfaction fully mediates the 
relationship between distributive injustice and organizational commitment. However, it merely provides partial mediation for the relationship between interactional injustice and organizational commitment. The summary of the results is presented in Figure 2.

Table 4: Summary of Hierarchical Regression

\begin{tabular}{lrrr}
\hline \hline Variables & Organizational Commitment & Turnover Intention & Job Satisfaction \\
\hline Distributive Injustice & $-.41^{* * *}$ & $.35^{* * *}$ & $-.54^{* * *}$ \\
Procedural Injustice & -0.05 & -0.11 & $-.10^{*}$ \\
Interactional Injustice & $-.48^{* * *}$ & $.40^{* * *}$ & $-.39^{* * *}$ \\
\hline $\mathrm{R}^{2}$ & 0.66 & 0.53 & 0.78 \\
$\mathrm{~F}$ Value & 130.5 & 74.42 & 228.88 \\
Durbin-Watson Statistic & 1.75 & 1.87 & 1.99 \\
Distributive Injustice & -0.03 & $.23^{* *}$ & \\
Procedural Injustice & 0.02 & 0.08 & \\
Interactional Injustice & $-.20^{* * *}$ & $.31^{* * *}$ & \\
Job Satisfaction & $.71^{* * *}$ & $-.23 *$ & \\
\hline $\mathrm{R}^{2}$ & 0.78 & 0.54 & \\
F Value & 172.66 & 57.43 & \\
Durbin-Watson Statistic & 1.94 & 1.85 & \\
\hline \hline
\end{tabular}

Note: $* \mathrm{p}<0.05 ; * * \mathrm{p}<0.01 ; * * * \mathrm{p}<0.001$.

Figure 2: The Mediating Effect of Job Satisfaction on the Relationship between Organizational Injustice and Organizational Commitment

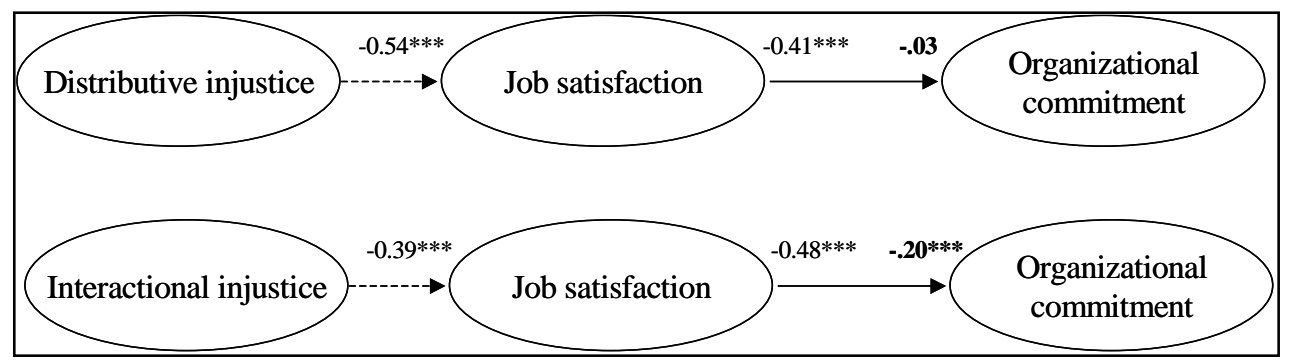

Hypothesis 4, suggesting job satisfaction mediates the relationship between organizational injustice and turnover intention, was supported. Both distributive and interactional injustice's effect on turnover intention was reduced from beta values of .35 and .40 to .23 and .31 , respectively. Overall, $\mathrm{R}^{2}$ improves slightly from .53 to .54 after the inclusion of job satisfaction as a mediator. In summary, the results have shown that job satisfaction partially mediates the relationship between distributive injustice and turnover intention and the relationship between interactional injustice and turnover intention. The summary of the results is presented in Figure 3 and Table 4. 
Figure 3: The Mediating Effect of Job Satisfaction on the Relationship between Organizational Injustice and Turnover Intention

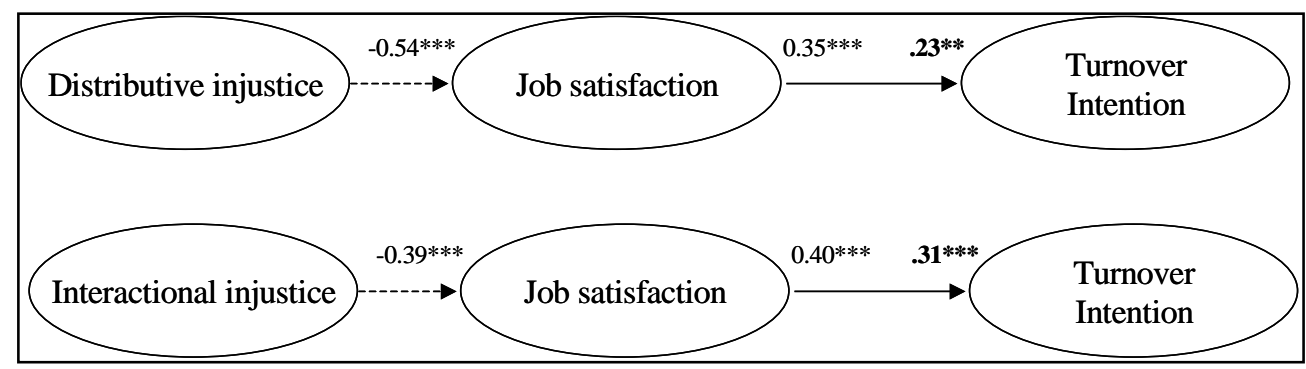

Hypotheses 5 and 6 examine the moderating effect of gender on the relationships between organizational injustice and organizational commitment and turnover intention. The summary results from the hierarchical regression tests are presented in Table 5. While results showed that all three dimensions of organizational injustice significantly predicted organizational injustice and turnover intention, there is no main effect for gender as the beta values are only -.03 and -.00 , as shown in step 2. The results demonstrated that organizational commitment was not higher for females than males, and neither was turnover intention higher among females than males. Only two interaction terms were found to be statistically significant. The findings revealed that gender moderates the relationship between distributive injustice and turnover intention $(\mathrm{p}<.05)$ and the relationship between interactional injustice and turnover intention $(\mathrm{p}<.05)$. The result means that distributive injustice was more strongly associated with the turnover intention for males than females. The results also showed that interactional injustice was more strongly associated with females' turnover intention than males. The interaction pattern is shown in Figures 4 and 5.

Table 5: Summary of the Moderating Effect of Gender

\begin{tabular}{|c|c|c|c|}
\hline \multicolumn{2}{|c|}{ "Organizational Commitment } & \multicolumn{2}{|c|}{ Turnover Intentions } \\
\hline Variable entered & Beta & Variable entered & Beta \\
\hline Step $1\left(\mathrm{R}^{2}=.68\right)$ & & Step $1\left(\mathrm{R}^{2}=.53\right)$ & \\
\hline DIJ & $-.41 * * *$ & DIJ & $.35 * * *$ \\
\hline PIJ & -.05 & PIJ & .11 \\
\hline InterIJ & $-.48 * * *$ & InterIJ & $.40 * * *$ \\
\hline Step $2\left(\mathrm{R}^{2}\right.$ change $\left.=.00\right)$ & & Step $2\left(\mathrm{R}^{2}\right.$ change $\left.=.00\right)$ & \\
\hline Gender & -.03 & Gender & .00 \\
\hline Step $3\left(\mathrm{R}^{2}\right.$ change $\left.=.01\right)$ & & Step $3\left(\mathrm{R}^{2}\right.$ change $\left.=.02\right)$ & \\
\hline DIJxGender & .18 & DIJxGender & $-.45^{*}$ \\
\hline PIJxGender & -.17 & PIJxGender & .15 \\
\hline InterIJxGender & -.20 & InterIJxGender & $.45^{*}$ \\
\hline
\end{tabular}

Note: $\mathrm{N}=203 ; * \mathrm{p}<.05, * * \mathrm{p}<.01, * * * \mathrm{p}<.001$; DIJ: distributive injustice, PIJ: procedural injustice, InterIJ: Interactional injustice, OC: organizational commitment, TI: turnover intention. 
Figure 4: The Moderating Effect of Gender on the Relationship Between Distributive Injustice and Turnover Intention

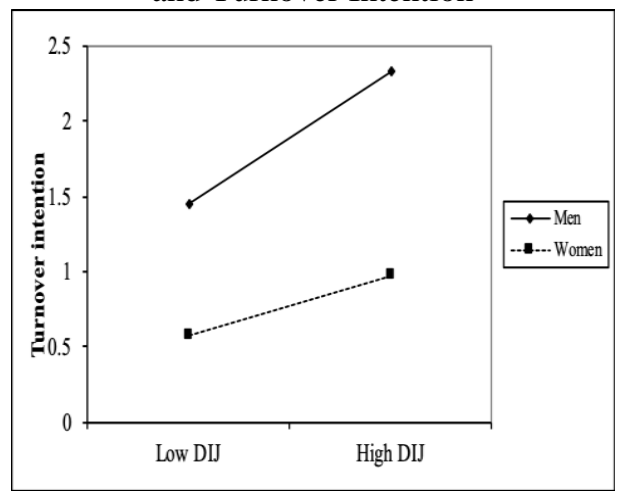

Figure 5: The Moderating Effect of Gender on the Relationship Between Interactional Injustice and Turnover Intention

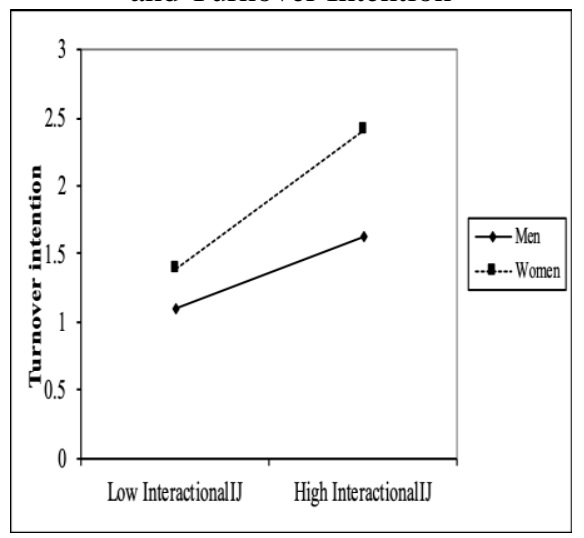

\section{DISCUSSION AND CONCLUSION}

Past research has suggested that organizations, especially managers, need to be aware, understand, and always seek ways to minimize organizational injustice to prevent unconstructive behavioral responses. Of the three organizational injustice elements, only distributive and interactional injustice were strongly correlated to organizational commitment. The finding indicates that the higher the perceived injustice among employees, the lower the organizational commitment level. The results obtained have shown support for previous research, which studied the relationships between injustice and organizational commitment (Cohen-Charash \& Spector, 2001; Colquitt et al., 2001).

The results suggest that organizations should focus on employees' perceptions, especially when it comes to reward distribution and the quality of interpersonal and informational communication or treatment that the employees received. In other words, employees' perceptions of fairness in 
terms of compensation may be associated with their well-being, and consequently, it will increase their commitment level. Employees tend to feel less committed when they perceive that they are not compensated fairly. If employees discover that they are not compensated fairly, they either quit the organization to join another or, if this is not feasible, they accept the compensation and at the same time feel less committed to the organization. On the other hand, obtaining fair compensation operates to further their obligation to the organization, and this commitment is strengthened. In other words, compensation, one of the critical HRM practices which influence the strength of a person's attachment and obligation to an organization, needs to appear fair. These findings illustrate that HRM practices, particularly compensation, that are perceived as fair and equitable may enhance organizational commitment. These factors will ultimately influence the type of behavioral response that employees display at their workplace. Once the employees perceive that they are being mistreated, their faith and overall acceptance of the organizational goal and objectives will reduce along with their willingness to go beyond the call of duty. Eventually, the intention to remain in the organization will wither as well, and when this happens, employees' level of organizational commitment on the job has been reduced significantly.

Given that responses to the quantitative survey showed that approximately $60 \%$ of participants had less than five years working experience, and more than half were from lower levels of management and technical, one possible inference is that it is the lower management level that may be interested in developing social interaction fairness with their supervisors. In other words, they are seeking better visible outcomes and relationship fairness. To restate, employees react more strongly to distributive and interactional fairness in relation to procedural fairness. One possible reason could be that while employees in MNCs Malaysia might perceive procedural fairness as vital, the absence of fairness in terms of distribution and interactional resulted in less affection and obligation to the organization. Fair equity and interpersonal treatment are expected.

Among the injustice elements, employees' perception of how social interactions were carried out is especially critical. The findings of this study found support for earlier findings of the stronger influence of interactional injustice to organizational commitment as proposed by Cohen-Charash and Spector (2001) and Colquitt et al. (2001). The second finding focusing on the relationship between organizational injustice and turnover intention was also found to be consistent with results from past research (Cropanzano \& Ambrose, 2001; Moorman, 1991; Lind et al., 1990; Phillips et al., 2001; Cohen-Charash \& Spector, 2001; Colquitt et al., 2001). In detail, the result found that two dimensions of organizational injustice were positively correlated to turnover intention. Specifically, only distributive and interactional injustice were significant predictors. In short, the result indicates that with a higher level of perceived injustice for these two dimensions, the intention to leave an organization will also be higher.

In other words, once employees feel that they are unfairly treated, their propensity to leave the organization will increase. Besides, once employees consider other employment alternatives, the level of commitment to the job may be reduced (Porter et al., 1974). The third finding found that both distributive and interactional injustice caused lower organizational commitment with job satisfaction as a mediator. Job satisfaction fully mediates the relationship between distributive injustice and commitment but partially mediated the relationship between interactional injustice and organizational commitment. This finding indicated that when employees perceive unfairness related to outcome/reward allocation or social enactment of formal procedures at the workplace, they will feel dissatisfied, eventually leading to a lower commitment to the organization. In other 
words, job satisfaction is proven to be an antecedent of organizational commitment consistent with past research done by Steers (1977) and Vandenberg and Lance (1992). Another significant finding found that job satisfaction partially mediated the relationship between injustice and turnover intention. In detail, the result showed that a higher perception of distributive and interactional injustice would lead to higher turnover intention among employees. In other words, employees who feel that they are being marginalized or unfairly treated would become dissatisfied and ultimately develop withdrawal behaviors, which demonstrated an increase in turnover intention. This finding is consistent with the results of past research by (Horn \& Griffeth, 1995).

This study examined job satisfaction as a mediator in the relationships between organizational injustice, organizational commitment, and turnover intention. Both distributive and interactional injustice caused lower organizational commitment with the presence of job satisfaction as a mediator. Job satisfaction fully mediates the relationship between distributive injustice and commitment but partially mediated the relationship between interactional injustice and organizational commitment. This finding indicated that when employees perceive unfairness related to outcome/reward allocation or social enactment of formal procedures at the workplace, they will feel dissatisfied, eventually leading to a lower commitment to the organization. In other words, job satisfaction is proven to be an antecedent of organizational commitment consistent with past research done by Steers (1977) and Vandenberg and Lance (1992). Job satisfaction was found to mediate the relationship between injustice and turnover intention partially. In detail, the result showed that a higher perception of distributive and interactional injustice would lead to higher turnover intention among employees. In other words, employees who feel that they are being marginalized or unfairly treated would become dissatisfied and ultimately develop withdrawal behaviors, which demonstrated an increase in turnover intention. This finding is consistent with the results of past research (Horn \& Griffeth, 1995). Job satisfaction was found to have a direct positive influence or serve as an antecedent of organizational commitment. Job satisfaction was also found to have a negative effect on turnover intentions. The results of this study support previous empirical evidence (Abraham, 1999; Glisson \& Durick, 1988; Griffeth et al., 2000; Mannheim et al., 1997). The theoretical framework developed for this study has some contribution to research in this field of study. The results again proved that when employees feel that they are being treated unfairly, they suffer a loss of job satisfaction, leading to reduced organizational commitment and increased turnover intention.

Lastly, this study showed that females did not have a higher commitment than males, contrary to previous research results. Neither was females more likely to develop turnover intention compared to their male counterparts. However, this study found that distributive injustice was more strongly associated with males' turnover intention than females. When it comes to the perception of interactional injustice, the results showed that interactional injustice was more strongly associated with females' turnover intention than males.

The results of this study provided both theoretical and practical implications. First, this study represents the theoretical or empirical research regarding the consequences of organizational injustice in the semiconductor industry. Although organizational justice is a prominent factor influencing organizational behavior (Greenberg, 1993), there have been very few empirical studies on organizational injustice issues in the semiconductor industry. This study's findings have proved that perceived injustice or unfairness at the workplace would always lead to adverse 
behavioral responses and an unfavorable impact on organizational outcomes. Nonetheless, employees' behavioral response is subjected to the actions taken by the management of the organization. While the management can ensure employees are treated fairly, measures to prevent unfairness must be developed to ensure all levels of employees are protected. The integrity of the management is upheld when it comes to the topic of fairness. Apart from formulating fair practices, this study also proved that it is essential for managers today to ensure that their actions are always perceived as fair. Managers must also maintain a positive perception of justice at reasonably high levels to help create a positive justice environment at the workplace that would ultimately lead to increased employee commitment and reduced turnover intentions (Ansari et al., 2007).

Secondly, this study has contributed to the literature by demonstrating that employees' perception of distributive and interactional injustice leads to job dissatisfaction. These feelings of dissatisfaction will eventually lead to a reduction of commitment level and increase turnover intention. If employees perceive fairness in interpersonal communication with respect to organizational procedures and outcomes, interactional justice is believed to exist. These results are consistent with past research findings (Cohen-Charash \& Spector, 2001; Colquitt et al., 2001). However, the findings have also shown that procedural injustice is not the primary concern in influencing employees' negative behavioral responses, which was generally found in past research. While distributive injustice refers to the perceived unfairness of the amounts of reward employees receive, procedural injustice is defined as the perceived unfairness of the means used to determine those amounts (Folger \& Konovsky, 1989). For example, when employees observe fairness in salary outcomes, there is a perception that distributive justice exists. However, employees may not be motivated to leave the organization even if they perceived unfairness in deriving these allocations. This implies that if the reward or the outcome is perceived as fair, employees will not feel that they are subjected to unfair treatment. Thus, At the same time, the organization should not neglect the interactional dimension of injustice at the workplace because when employees are treated with respect, dignity and given sufficient information when it comes to the way information is communicated. They are not inclined to engage in negative behavioral responses. More importantly, supervisors and managers must realize that they cannot afford to neglect the importance of interpersonal relationships.

Thirdly, this study used turnover intention as an indicator of withdrawal behavior in an organizational setting. While employee turnover is a big concern for the most organization, it is predominantly important in MNCs, especially in the semiconductor industry, mainly because of the high amount of complexity and specialization involved in the business, which in turn costs organizations a considerable amount of resource and capital investment spent specifically in employee recruitment, training, and development. In this aspect, this study has proved that while perceived distributive and interactional injustice will increase turnover intention, the impact is more severe when employees are dissatisfied with their job. Similarly, the study showed that job satisfaction plays a role in influencing organizational commitment if perceived unfairness in the workplace.

Fourthly, findings from this study provided managers in the semiconductor industry with information into employee's fairness perception pattern and some guidelines in managing employees by practicing and documenting organizational justice to inspire and attract positive attitude and behavioral response among employees. The findings also reveal that both 
distributive and interactional injustice dimensions substantially affect organizational commitment and turnover intention. Both these dimensions also have a much stronger effect on job satisfaction than procedural injustice. Procedural injustice in the meantime only influences job satisfaction. As mentioned, semiconductor/engineering-based organizations have a relatively volatile business trend with relatively long working hours, a highly challenging work nature, and require employees with highly specialized knowledge. Thus, given the nature of the work environment, the key attraction or focus may be on the incentive system. This could be in the form of a salary adjustment, a bonus, a stock option, a promotion, a better shift, and an extra day off. Whatever the incentive, it is vital that employees understand what the rewards are for and how the allocation was done. Similarly, it is crucial for employees to feel that the management is practicing the interpersonal and informational aspects of justice, mainly regarding communication with respect to organizational procedures.

Lastly, the study investigated gender as a moderator for the relationship between injustice and turnover intention and organizational commitment. In this aspect, this study has implications for the employee turnover intention and level of commitment in the semiconductor industry by providing contrary empirical evidence for those relationships that have been reported under other industries. Specifically, the present study found that organizational commitment was not higher for females than males, and similarly was the turnover intention is not higher among females than males. However, the results found that distributive injustice is more strongly associated with males' turnover intention than females. On the other hand, interactional injustice was more strongly associated with females' turnover intention than males.

In conclusion, this study investigates the relationship between organizational injustice, organizational commitment, and turnover intention. The study also examines the mediating role of job satisfaction and investigates whether gender plays a role in moderating the relationship. The results of this study provided significant insights into the employees' perception of injustice and organizational behaviors. Statistical tests conducted on the model indicated that only distributive and interactional injustice contributes to turnover intention and organizational commitment. Besides, this study also found that higher job satisfaction will contribute to higher organizational commitment. Still, on the other hand, lower job satisfaction will, in turn, cause high turnover intention among employees. Interestingly, the turnover intention was more strongly associated with distributive injustice for males compared to females. In contrast, interactional injustice was more strongly associated with the turnover intention for females than males. In short, these findings from this study provide guidelines to help managers better understand organizational behaviors, specifically on how to minimize employee turnover, improve job satisfaction and organizational commitment, and at the same time make better decisions pertaining to outcomes and interactional aspects when dealing with their employees.

\section{REFERENCES}

Abraham, R. (1999). The impact of emotional dissonance on organizational commitment and intention to turnover. The Journal of Psychology, 133(4), 441-455.

Al-Dmour, H., \& Awamleh, R. A. (2002). Effects of transactional and transformational leadership styles of sales managers on job satisfaction and self-perceived performance of salespeople: A 
study of Jordanian manufacturing public shareholding companies, Dirasat. Administrative Sciences Series, 29(1), 247- 261.

Angle, H. L., \& Perry, J. L. (1981). An empirical assessment of organizational commitment and organizational effectiveness. Administrative Science Quarterly, 26, 1-14.

Ansari, M. A., Kee, D. M. H., \& Aafaqi, R. (2007). Leader-member exchange and attitudinal outcomes: Role of procedural justice climate. Leadership and Organization Development, 28(8), 690-709.

Ansari, M. A., Kee D. M. H., \& Aafaqi, R. (2008). Fairness of HRM practices and commitment: The mediating impact of procedural justice climate. FWU Journal of Social Science, 2, 317.

Bies, R. J., \& Moag, J. S. (1986). Interactional justice: Communication criteria of fairness. In R. J. Lewicki, B. H. Sheppard, \& M. H. Bazerman (Eds.), Research on negotiation in organizations (pp.43-55). Greenwich: JAI Press.

Bies, R. J., \& Tripp, T. M. (2001). A passion for justice: The rationality and morality of revenge. In R. Cropanzano (Ed.), Justice in the workplace: From theory to practice (pp.3-26). NJ: Erlbaum.

Blau, P. (1964). Exchange and power in social life. New York: John Wiley \& Sons.

Bluedorn, A. C. (1982). A unified model of turnover from organizations. Human Relations, 35, 135-153.

Chen, J., Silverthorne, C., \& Hung, J. (2006). Organization communication, job stress, organizational commitment, and job performance of accounting professionals in Taiwan and America. Leadership and Organization Development Journal, 27(4), 242-249.

Cohen-Charash, Y., \& Spector, P. E. (2001). The role of justice in organizations: A metaanalysis. Organizational Behavior \& Human Decision Processes, 86(2), 278-321.

Cohen, R. L. (1986). Justice: Views from the social sciences. New York: Plenum.

Colquitt, J. A., Conlon, D. E., Wesson, M. J., Porter, C. O. L. H., \& Ng, K. Y. (2001). Justice at the millennium: A meta-analytic review of 25 years of organizational justice research. Journal of Applied Psychology, 86(3), 425-445.

Cropanzano, R., \& Ambrose, M. L. (2001). Procedural and distributive justice are more similar than you think: A monistic perspective and a research agenda. In J. Greenberg \& R. Cropanzano (Eds), Advances in Organizational Justice (pp.119-151). Stanford: Stanford University Press.

Cugueró-Escofet, N., Ficapal-Cusí, P., \& Torrent-Sellens, J. (2019). Sustainable human resource management: How to create a knowledge sharing behavior through organizational justice, organizational support, satisfaction, and commitment. Sustainability, 11(19), 1-20. doi: $10.3390 /$ su11195419.

Folger, R., \& Konovsky, M. A. (1989). Effects of procedural and distributive justice on reactions to pay raise decisions. Academy of Management Journal, 32(1), 115-130.

Glisson, C., \& Durick, M. (1988). Predictors of job satisfaction and organizational commitment in human service organization. Administrative Science Quarterly, 33, 61- 81.

Greenberg, J. (1993). The social side of fairness: Interpersonal and informational causes of organizational justice. In R. Cropanzano (Ed.), Justice in the workplace: Approaching fairness in human resource management. Hillsdale, NJ: Erlbaum.

Greenberg, J., \& Baron, R. A. (1997). Behavior in organizations: Understanding and managing the human side of work (6th ed.). Upper Saddle River, NJ: Prentice-Hall. 
Griffeth, R. W., Hom, P. W., \& Gaertner, S. (2000). A meta-analysis of antecedents and correlates of employee turnover: Update, moderator tests, and research implications for the next millennium. Journal of Management, 26(3), 463-488.

Horn, P., \& Griffeth, R. (1995). Employee turnover. South-Western College, Cincinnati, OH.

Kee, D. M. H., Ansari, M. A., \& Aafaqi, R (2004). Fairness of human resource management practices, leader-member exchange, and organizational commitment. Asian Academy of Management Journal, 9(1), 99-120.

Kee, D. M. H., Ching, S. L., \& Ravindran, T. (2020). The influence of HIHRM practices on employee attitude and behavior. International Journal of Advanced Science and Technology, 29(8), 2438-2447.

Kaul, S., \& Singh, A. (2017). Organizational justice as a predictor of organizational commitment in automobile dealerships in Delhi, national capital region. Journal of the Indian Academy of Applied Psychology, 43(2), 230-238.

Kauppila, O. P., Ehrnrooth, M., Makela, K., Smale, A., Sumelius, J., \& Vuorenmaa, H. (2018). Serving to help and helping to serve: Employee reactions to HR manager servant leadership. In Academy of Management Proceedings. NY: Briarcliff Manor.

Lance, C. E. (1991). Evaluation of a structural model relating job satisfaction, organizational commitment and precursors to voluntary turnover. Multivariate Behavioral Research, 1, 137-162.

Lind, E. A., Kanfer, R., \& Earley, P. C. (1990). Voice, control, and procedural justice: Instrumental and non-instrumental concerns in fairness judgments. Journal of Personality and Social Psychology, 59, 952-959.

Luo, Z., Marnburg, E., \& Law, R. (2017). Linking leadership and justice to organizational commitment: The mediating role of collective identity in the hotel industry. International Journal of Contemporary Hospitality Management, 29(4), 1167-1184.

Major, B., \& Deaux, K. (1982). Individual differences in justice behavior. In J. L. Greenberg \& R. L. Cohen (Eds.), Equity and justice in social behavior. New York: Academic Press.

Mannheim, B., Baruch, Y., \& Tal, J. (1997). Alternative models for antecedents and outcomes of work centrality and job satisfaction of high-tech personnel. Human Relations, 50, 1537 1562.

Mitchell, T., Holtom, B., Lee, T., Sablynski, C., \& Erez, M. (2001). Why people stay: using job embeddedness to predict voluntary turnover. Academy of Management Journal, 44(6), 1102-1121.

Mobley, W. H., Horner, S. O., \& Hollingsworth, A. T. (1978). An evaluation of precursors of hospital employee turnover. Journal of Applied Psychology, 63, 408-414.

Moorman, R. H. (1991). Relationship between organizational justice and organizational citizenship behaviors: Do fairness perceptions influence employee citizenship? Journal of Applied Psychology, 76(6), 845-855.

Mowday, R. T., Porter, L. W., \& Steers, R. M. (1982) Employee-organization linkages: The psychology of commitment, absenteeism, and turnover. New York: Academic Press.

Mowday, R. T., \& Steers, R. M. (1979). The measurement of organizational commitment. Journal of Vocational Behavior, 14, 224-247.

Niehoff, B. P., \& Moorman, R. H. (1993). Justice as a mediator of the relationship between methods of monitoring and organizational citizenship behavior. Academy of Management Journal, 36(3), 527-556. 
Paul, G. D., \& Kee, D. M. H. (2018). Human resource management practices and turnover intention: The mediating role of perceived organizational support in tertiary institutions in Nigeria. International Journal of Engineering \& Technology, 7, 715-722.

Paul, G. D., \& Kee, D. M. H. (2020). HR, workplace bullying, and turnover intention: The mediating role of work engagement. Journal of Environmental Treatment Techniques, 8(1), 23-27.

Phillips, J., Douthitt, E., \& Hyland, M. (2001). The role of justice in team member satisfaction with the leader and attachment to the team. Journal of Applied Psychology, 86, 316-325.

Pillsbury, C. M., Capozzoli, L., \& Ciampa, A. (1989). A synthesis of research studies regarding the upward mobility of women in public accounting. Accounting Horizons, 3(1), 63-70.

Porter, L. W., Steers, R. M., Mowday, R. T., \& Boulian, P. V. (1974). Organizational commitment, job satisfaction, and turnover among psychiatric technicians. Journal of Applied Psychology, 59, 603-609.

Price, J. L., \& Mueller, C. W. (1981). A causal model of turnover for nurses. Academy of Management Journal, 24, 543-565.

Rasch, R. H., \& Harrell, A. (1990). The impact of personal characteristics on the turnover behavior of accounting professionals. Auditing: A Journal of Practice and Theory, 9(1), 90-102.

Rubel, M. R. B., \& Kee, D. M. H. (2015a). Perceived fairness of performance appraisal, promotion opportunity, and nurses' turnover intention: The role of organizational commitment. Asian Social Science Journal, 11(9), 183-197.

Rubel, M. R. B., \& Kee, D. M. H. (2015b). High commitment compensation and employee turnover intention: Mediating effect of job satisfaction. Mediterranean Journal of Social Science, 6(4), 321-332.

Rubel, M. R. B., Kee, D. M. H., \& Rimi, N. N. (2017). The mediating role of work-family conflict on role stressors and employee turnover intention relationship in labor-oriented organizations. Global Business Review, 18(6), 1384-1399.

Rubel, M. R. B., Kee, D. M. H., \& Rimi, N. N. (2020). Matching people with technology: Effect of high involvement work practice on technology adaptation. South Asian Journal of Human Resources Management, 7(1), 9-33.

Rubel, M. R. B., Rimi, N. N., Yusof, Y., \& Kee, D. M. H. (2018). High commitment human resource management practices and employee service behavior: trust in management as mediator. IIMB Management Review, 30(4), 316-329.

Steers, R. (1977). Antecedents and outcomes of organizational commitment. Administrative Science Quarterly, 22, 46-56.

Sweeney, P. D., \& McFarlin, D. B. (1997). Process and outcome: Gender differences in the assessment of justice. Journal of Organizational Behavior, 18, 83-98.

Vandenberg, R., \& Lance, C. (1992). Examining the causal order of job satisfaction and organizational commitment. Journal of Management, 18(1), 153 - 167.

Williams, L. J., \& Hazer, J. T. (1986). Antecedents and consequences of satisfaction and commitment in turnover models: A re-analysis using latent variable structural equation methods. Journal of Applied Psychology, 71, 219-231. 